\title{
Technical Efficiency in Cotton Production: The Role of Premium Payments in Turkey
}

\author{
Ebru Guven Solakoglu • Sabri Er • \\ M. Nihat Solakoglu
}

\begin{abstract}
Providing about two million employments from textile to agriculture, cotton is an important and a strategic product for Turkey. Thus, support programs become critical and crucial for the cotton production. For cotton farmers, premium payments affecting the cost measures become vital next to the market prices. This study measures the technical efficiency of cotton production, incorporating support premium payments as one of the background variables to capture the effect of premiums on efficiency scores for cotton production using stochastic frontier model. The premium payments found to be the most important determinant of inefficiencies, and the results of our analysis suggest that premiums paid to farmers increase efficiency for cotton production. In addition, regional production was important explaining inefficiencies. Although three regions in Turkey did not behave parallel and showed different characteristics in production, efficiency gap between these regions is closed recently.
\end{abstract}

Keywords Cotton technical efficiency · Premium payments · Turkey

JEL classification Q14 $\cdot$ Q16

E. G. Solakoglu $(\bowtie) \cdot$ M. N. Solakoglu

Banking and Finance Department, Bilkent University, Ankara, Turkey

e-mail: egsolakoglu@bilkent.edu.tr

M. N. Solakoglu

e-mail: nsolakoglu@bilkent.edu.tr

S. Er

Ankara Development Agency, Ankara, Turkey

e-mail: sabrier@ankaraka.org.tr 


\section{Introduction}

Turkey is a major cotton producer, next to China, Pakistan and India, and is ranked eighth in the world with a $3.5 \%$ share of total production. With respect to unit area yield, she is ranked third; and ranked fourth in terms of consumption. Turkey's export of cotton is minimal since its production has been insufficient to meet increasing cotton demand due to large textile industry, and imports cotton as needed to supply its textile industries. ${ }^{1}$

Cotton is an important and a strategic product that feeds many industries. It can be considered both as a fiber crop and an oil crop. After the ginning process of raw cotton, the fiber is used mostly in textile industry, and its crust is used as an animal food (oil cake and pulp). It is also used as cotton seed to be used in oil industry, as crude oil to produce refined oil such as margarine oil and refined liquid, and soapstock, and as linter to feed bed and filling industry, war industry and cellulose chemical industry. Although its share in world merchandize trade is insignificant ( 0.10 to $0.15 \%$ from 1990 to 2008), cotton is a significant crop to a number of developing countries with its substantial contribution to the labor industry and hence, to gross domestic production (GDP). For example, in Turkey, it provides about two million employments from textile to agriculture.

In Turkey, the acreage for cotton production has increased slightly in the last decades, parallel with the production levels, whereas yield increased much more. For example, from 1991 to 2008, the cultivated area decreased by $17 \%$, the

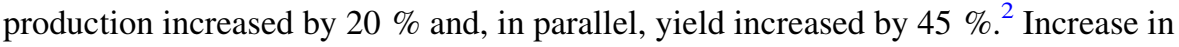
yield is based on irrigated farming, high quality certificated seed use, application of new technologies in production, and increased in awareness of the producers and cotton premium system.

Market prices of the products are the most important indicator for farm's decisions to cultivate. If the market price is below the cost of production, then there is no incentive for the farmer to continue to cultivate the product. Instead, farmer can decide to cultivate a substitute product in place. However, the existence of support premiums can impact that decision process since the effective price that farmer faces, market price plus the support premium, will most likely be larger than the production cost even when the market prices are lower than the production cost. The major reason behind high production costs is high input costs and the lack of high-technology use in almost every step of cotton production. Moreover, huge support volume and distorting policies such as high domestic support and export subsidies in the European Union and particularly in the United States have caused sharp fall in the world cotton prices resulting in virtually impossible competition for producers in developing countries. Hence, the pressure on market prices of cotton makes the producers worse off.

Turkey had guaranteed purchased scheme between 1961 and 1980 to support cotton production. After 1980, this system turned to be a support purchase price

\footnotetext{
1 Source: Ministry of Agricultural and Rural Affairs of Turkey (MARA, www.tarim.gov.tr); General Directorate of Agricultural Production and Development (TUGEM, www.tugem.com.tr).

2 Source: Turkish Statistical Institute, www.tuik.gov.tr.
} 
system, and this system continued until 1993. The basis of cotton production support depended on the agriculture sales cooperatives, ANT Birlik, ${ }^{3}$ CUKOBIRLIK $^{4}$ and TARIS ${ }^{5}$. Members of these cooperatives are cotton producers and they have a role of marketing the produced cotton, acting as a partner to make a purchase as a partner or an agent over prices announced, store the product, construct and run processing plant, and sell the product. Thus, they have an impact on markets and price strategies, and efficiency. In 1994, support policies are taken under reconsideration and discipline. The premium system was implemented in 1993, and its function was to determine the target and intervention price on the base of premium payments, difference to be paid by the government. In 1998, support price system was resumed by the Ministry of Agriculture and Rural Affairs comprising direct income support system. As of today, input support scheme for fertilizer, certified seed and diesel (gas) along with premium system are being used to support cotton production.

There is a vast amount of work measuring efficiency for many products in various industries. Most of the work in the literature applies data envelopment analysis (DEA) to measure efficiency for different agricultural products such as hazelnut, cotton, etc. Some recent examples are Kilic et al. (2009), Gul et al. (2009), Alemdar and Oren (2006), etc. DEA is a linear programming to construct a non parametric frontier over the data to calculate efficiencies relative to the frontier, thus provides an assessment of each farm's technical performance. It is favored because of its nonparametric approach and ability to handle multiple inputs and multiple outputs. This method, however, is criticized of producing biased estimates when there is measurement error or statistical noise.

Another approach to measure efficiency is to use stochastic frontier analysis (SFA). SFA differs from DEA by including a stochastic component that describes random shocks, which are not directly attributable to the production or the underlying technology, affecting production process. It is a regression based approach that assumes two unobserved error terms representing efficiency and statistical noise. Thus, this method is parametric and requires specifications of the error distribution. Nonetheless, panel data version of stochastic frontier model works well in achieving relatively high rank correlations between estimated and true efficiency.

This study measures the technical efficiency of cotton production and questions the role of premium payments to farmers on efficiency. Studies of effects of support policies on efficiency are almost non-existing in the literature. Support policies affect the cost measures, and hence the production decisions. Therefore, it is quite possible that such policies may affect efficiency since they affect the farmers' decisions and the calculated efficiencies may be overestimated. In view of that, this study differs from the other studies in two respects. First, we use stochastic frontier

\footnotetext{
3 ANTBirlik has 6 cotton agricultural sales cooperatives located in the Mediterranean region, central location in Antalya.

${ }^{4}$ CUKOBIRLIK has 35 cotton (along with peanuts and soybeans) agricultural sales cooperatives located in the Cukurova and Southeastern Anatolia region, central location in Adana.

5 TARIS has 44 cotton agricultural sales cooperatives located in the Aegean region, central location in Izmir.
} 
in calculating the efficiencies, therefore incorporate some background variables to capture efficiency differentials. Second, we include support premium payments as one of the background variables and to capture the effect of premiums on efficiency scores for cotton production.

The remainder of the study is as follows: we describe the data and explain the methodology in the second section. The results are presented in the third section. We include our discussions in this section as well. Fourth section concludes the study.

\section{Data and the Methodology}

The data consists of cotton production from 2001 to 2008 in 14 cities located in three different regions in Turkey. The cities we put into our analysis are from the Agean region (Aydin, Denizli, Mugla, Izmir, Manisa), Southeastern Anatolia region (Sanli Urfa, Gazi Antep, Diyarbakir, Mardin), and Mediterranean region (Osmaniye, Kahramanmaras, Adana, Antalya, Hatay). Mediterrenean region (as called Cukurova) was the leading region in cotton production because of its ecological position until recently. The leading region today is the Southeastern Anatolia region as three hundred thousands of hectares of land opened to irrigation in this region. In addition, the farms in this region are larger in size, labor is cheap, and farmers are interested in this fairly new crop they produce. Moving the production to this region was also an inevitable result of long-time farming without altering the crops in the other regions. Long-time farming of cotton caused diseases and pests in the production process, which leaded a decrease in quantity and quality of cotton in these regions. However, highest quality cotton is produced in the Aegean region.

Of the total cost of produced cotton, acreage accounts for, on average, $84 \%$, and the remaining $12 \%$ is shared by various costs in production. Hence, acreage used for cotton production (X1), labor cost (X2), fertilizer cost (X3), seed cost (X4), water usage (irrigation) (X5), pesticide cost (X6), are taken as explanatory variables of cotton yield (kilograms). All the costs are in local currency, Turkish Liras (TL). Table 1 presents descriptive statistics of these variables.

To understand the efficiency differentials, we should also take the characteristics of the production into account. As we mentioned above, the composition of regional production changes due to long-time farming. The size of the farms, which somehow reflect the mechanization in production, is also an important factor. But most of all,

Table 1 Descriptive statistics for the production variables in the model

\begin{tabular}{|c|c|c|c|c|c|c|c|}
\hline & $\begin{array}{l}\text { Y } \\
\text { Yield }\end{array}$ & $\begin{array}{l}\text { X1 } \\
\text { Acreage (ha) }\end{array}$ & $\begin{array}{l}\mathrm{X} 2 \\
\text { Labor cost }\end{array}$ & $\begin{array}{l}\text { X3 } \\
\text { Fertilizer cost }\end{array}$ & $\begin{array}{l}\text { X4 } \\
\text { Seed cost }\end{array}$ & $\begin{array}{l}\text { X5 } \\
\text { Water cost }\end{array}$ & $\begin{array}{l}\text { X6 } \\
\text { Pesticide cost }\end{array}$ \\
\hline Median & 79.43 & 20,379 & 14.29 & 4.14 & 2.32 & 3.01 & 2.22 \\
\hline Mean & 150.06 & 37,677 & 31.90 & 8.89 & 5.72 & 9.62 & 4.75 \\
\hline Std dev & 186.73 & 45,603 & 49.07 & 14.16 & 7.00 & 22.97 & 5.60 \\
\hline
\end{tabular}

Ministry of agriculture and rural affairs. Costs are in million TL, and yield is in million kilograms ha hectare 
premium payments are the key factor for farmers' cultivation decisions. All these considerations lead us to apply a stochastic frontier specification for our analysis.

Stochastic frontier specification of a production function allows the error to be divided into an inefficiency component, which may represent random effects beyond the control of the economy. This decomposition of the error term, developed by Battese and Coelli (1992), allows for the simultaneous estimation of the production function and the inefficiency function. ${ }^{6}$

$$
\begin{aligned}
\ln Y_{i t}= & \beta_{0}+\beta_{1} \ln X_{1 i t}+\beta_{2} \ln X_{2 i t}+\beta_{3} \ln X_{3 i t}+\beta_{4} \ln X_{4 i t}+\beta_{5} \ln X_{5 i t}+\beta_{6} \ln X_{6 i t} \\
& +\varepsilon_{i t}
\end{aligned}
$$

where $\mathrm{i}$ denotes the city; $\mathrm{t}$ denotes time; ln represents the natural logarithm; $\mathrm{Y}_{\mathrm{it}}$ is cotton yield in kilograms at time $t$ and for city $i$; $X_{1}$ is acreage devoted for cotton production; $\mathrm{X}_{2}$ represents the labor cost measured by local currency; $\mathrm{X}_{3}$ is cost for fertilizer in local currency; $\mathrm{X}_{4}$ is cost for seed in local currency; $\mathrm{X}_{5}$ is cost for irrigation in local currency; $\mathrm{X}_{6}$ is cost for pesticide in local currency. Following Battese and Coelli (1995), the error term is defined as $\varepsilon_{i}=V_{i}-U_{i}$, where $V_{i}$ is the noise component and is independently and identically distributed with a $\mathrm{N}\left(0, \sigma_{\mathrm{v}}^{2}\right)$. The non negative $U_{i}$ error term has similar properties to the noise component, is independently and identically distributed with $\mathrm{N}\left(\mathrm{Z}_{\mathrm{i}} \delta, \sigma_{\mathrm{u}}^{2}\right)$. The mean of firm-specific technical inefficiency $\left(\mathrm{U}_{\mathrm{i}}\right), \mu_{\mathrm{i}}$, is defined as the following:

$$
\mu_{i}=\delta_{0}+\sum_{j=1}^{4} \delta_{j} Z_{i j}
$$

$\mathrm{Z}_{\mathrm{i}}$ is a vector of other factors that influence production directly, and are expected to present inefficiency. We introduce four inefficiency variables. $Z_{1}$ is a dummy variable representing the Southeastern Anatolia region. In the recent years, production moved to this area for two reasons, better climate conditions and irrigation. $Z_{2}$ is a dummy variable representing the Mediterranean region. $Z_{3}$ is a dummy variable representing the size of the farm, and finally $\mathrm{Z}_{4}$ representing the premium paid to the producers for cotton production.

\section{Results}

We estimate the parameters of the production frontier and predict individual technical efficiencies by the maximum likelihood method using FRONTIER 4.1 software. $^{7}$ The high Gamma value $\left(\gamma=\sigma_{\mathrm{v}}^{2} / \sigma^{2}\right)$ supports the importance of the inefficiency factors and found to be 0.90 , suggesting that of the variation in the composite error term is due to the inefficiency component. The results are presented in Table 2.

The sum of elasticities is 1.15 and it was not found to be statistically different from unity, using the t-statistic. Hence, we infer that the Turkish cotton industry has

\footnotetext{
${ }^{6}$ For a review of the theory and application of stochastic frontier models, see Coelli et al. (2005) and Kumbhakar and Knox Lovell (2003).

7 Coelli (1996).
} 
Table 2 Maximum likelihood estimates of the stochastic frontier function and technical inefficiency model for cotton production of Turkey

\begin{tabular}{llrr}
\hline & Parameter & Coeff.est. & t-stat \\
\hline Stochastic frontier & & & \\
Constant & $\beta_{0}$ & 6.623 & 53.12 \\
ln (acreage) & $\beta_{1}$ & 0.894 & 30.23 \\
ln (labor cost) & $\beta_{2}$ & -0.040 & -2.97 \\
ln (fertilizer cost) & $\beta_{3}$ & 0.074 & 2.32 \\
ln (seed cost) & $\beta_{4}$ & 0.044 & 1.99 \\
ln (water cost) & $\beta_{5}$ & 0.056 & 3.27 \\
ln (pesticide cost) & $\beta_{6}$ & -0.060 & -2.26 \\
Technical inefficiencies & & & \\
Constant & $\delta_{0}$ & 1.607 & 7.02 \\
Southeastern Anatolia & $\delta_{1}$ & 0.090 & 2.36 \\
Mediterranean region & $\delta_{2}$ & -0.177 & -4.85 \\
Farm size & $\delta_{3}$ & 0.007 & 0.23 \\
Premiums paid & $\delta_{4}$ & -0.072 & -4.16 \\
Variance parameters & & & \\
& $\sigma^{2}$ & 0.010 & 5.43 \\
& $\gamma$ & 0.997 & 14.50 \\
$\ln$ (likelihood) & & 101.29 & \\
\hline
\end{tabular}

operated at a constant returns-to-scale during the sampled years. To establish the significance of inefficiency effects, additional null hypotheses on inefficiency factors were also subjected to several tests, based on the generalized likelihood ratio. The results are presented in Table 3 .

The first null hypothesis specifies the absence of inefficiency factors (all inefficiency coefficients but the intercept are zero) and is strongly rejected. The second, third, and fourth hypotheses focus on the inefficiency factors separately. The fifth, sixth, and seventh hypotheses are to search for any evidence to conclude that pairs of inefficiency effects explain technical efficiency differentials. The third null hypothesis, which specifies no effect of the size of the farm, is the only factor that does not explain the TE differences of cotton production in Turkey. This result is consistent with the maximum likelihood estimates of the stochastic frontier function presented in Table 2.

It is interesting to find that the regional dummies do not behave parallel. The production in Mediterranean region has a positive effect on efficiency as seen in Table 2 (estimated inefficiency coefficient is negative) whereas the production in southeastern region affects efficiency negatively. This result is not surprising since recently the southeastern region became the leading cotton producing region, as a result of large increase in irrigation farming in the region, suitable for machinery harvesting, as well as negative effects of long-term non-altered cotton farming in the other regions. These factors took the leading position from the Mediterranean region although it has been the most suitable area ecologically. However, this does not mean that the efficiency can be achieved quickly. 
Table 3 Generalized likelihood-ratio tests of hypotheses for variables of inefficiency effects, cotton producers in Turkey

\begin{tabular}{lllllll}
\hline $\begin{array}{l}\text { Null hypothesis }\left(\mathrm{H}_{0}\right) \text { and } \\
\text { restrictions imposed }\end{array}$ & \multicolumn{2}{l}{ Likelihood ratio statistics } & \multicolumn{3}{c}{ Decision } \\
\cline { 2 - 6 } & Restricted & & Unrestricted & $L$ & $\chi_{0.99}^{2}$ & \\
\hline 1. No inefficiency factors & $\mathrm{dj}=0 ; \mathrm{j}=1,2,3,4$ & 65.05 & 101.29 & 72.48 & 7.82 & reject $\mathrm{H}_{0}$ \\
2. No region effect & $\mathrm{dj}=0 ; \mathrm{j}=1,2$ & 82.62 & 101.29 & 37.34 & 5.99 & reject $\mathrm{H}_{0}$ \\
3. No size effect & $\mathrm{dj}=0 ; \mathrm{j}=3$ & 101.43 & 101.29 & -0.28 & 3.84 & do not reject $\mathrm{H}_{0}$ \\
$\begin{array}{l}\text { 4. No premium effect } \\
\text { 5. No size and premium } \\
\text { effect }\end{array}$ & $\mathrm{dj}=0 ; \mathrm{j}=4$ & 82.66 & 101.29 & 37.26 & 3.84 & reject $\mathrm{H}_{0}$ \\
$\begin{array}{l}\text { 6. No region and } \\
\text { premium effect }\end{array}$ & $\mathrm{dj}=0 ; \mathrm{j}=3,4$ & 80.62 & 101.29 & 41.34 & 5.99 & reject $\mathrm{H}_{0}$ \\
$\begin{array}{l}\text { 7. No region and size } \\
\text { effect }\end{array}$ & $\mathrm{dj}=0 ; \mathrm{j}=1,2,4$ & 70.11 & 101.29 & 62.36 & 7.82 & reject $\mathrm{H}_{0}$ \\
\hline
\end{tabular}

Figure 1 shows the behavior of the average efficiency scores we estimated. As seen from the figure, in the beginning of the period in question, the efficiency gap is large between Aegean/Mediterranean region and Southeastern Anatolia region. In the Aegean region about fifty percent of the harvest is done by hand, and the rest is done by machines. The difference in regional efficiencies is mostly the result of ecological reasons and the conscience of the harvesting. In the Aegean region harvest is done two times annually and farmers are highly conscious and experience in harvesting. In the Southeastern Anatolia region, the harvest is done three times annually, but farmers in that region are not as experienced as the Aegean farmers. We also see that the efficiency gap closes between the regions except that in 2004 and 2005, the efficiency in Aegean region is about $15 \%$ higher than the other regions. The reason for that could be the warmer weather and late rain in those years.

Based on these findings, it appears that in terms of TEs, cotton farms have converged to their best-practice levels in each consecutive year over the eight years. This seems to be a clear adjustment process towards better relative efficiency levels, triggered perhaps by the eased support policies in the last years.

The premiums seem to be the most important determinant of inefficiencies. Its coefficient is negative and statistically significant, suggesting decreases in inefficiencies. Thus, premiums paid to farmers increase efficiency for cotton production. This result is not surprising since the cultivation area of cotton in Turkey has declined sharply in the last decade. One reason for that is the lower world prices and costly production of cotton, which caused high cost producers shift production into low cost alternatives. Hence, premiums paid to farmers ease farmers' decisions on cultivating cotton by lowering the effective cost of production. On the other hand, production decisions of alternative crops such as corn and soybeans are also an important factor on cotton production. Especially, lower costs and easy harvest of these alternative crops attract farmers to produce 


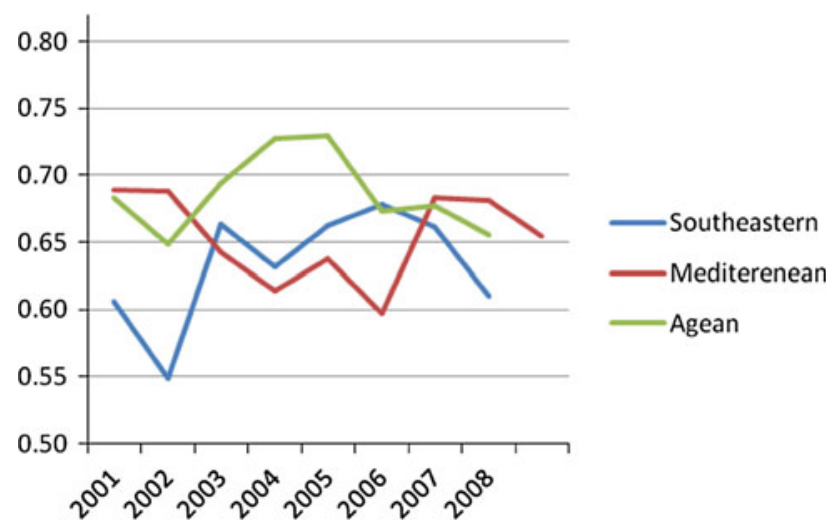

Fig. 1 Efficiency scores for three regions between 2001 and 2008
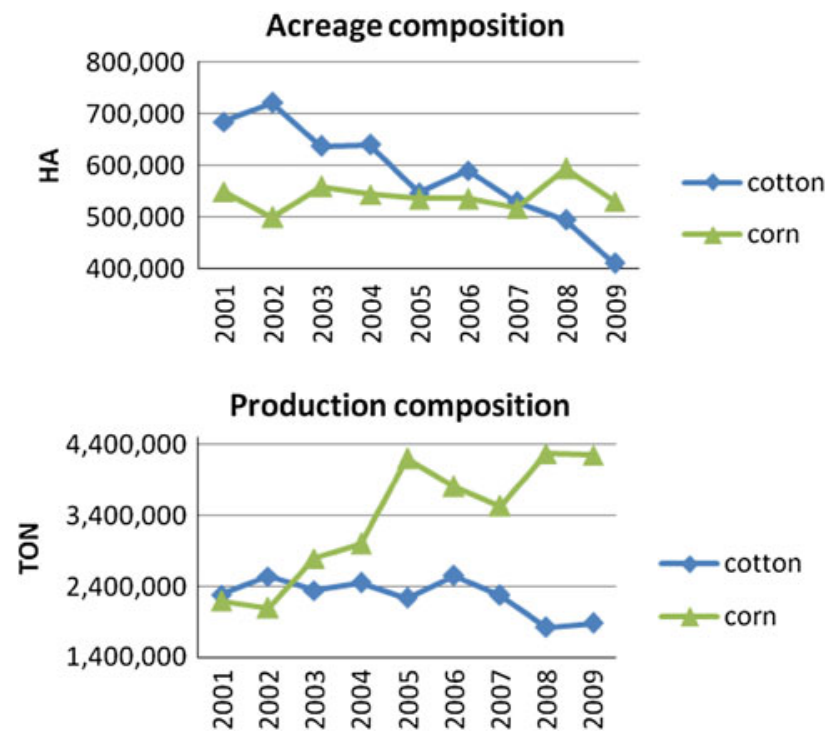

Fig. 2 The acreage and production of cotton and corn

these crops instead. The acreage and production of two alternative crops, cotton and corn, are shown in Fig. 2.

As seen from Fig. 2, acreage of cotton decreased about $40 \%$ from 2001 and 2009, whereas the production decreased more than $20 \%$ in that period. However, acreage for corn is volatile in that period, whereas the production almost doubled. Best ecological conditions, mechanization, use of certificated seed, adaptation of the crop, less pesticides during this period are the reasons for the increase in production.

Finally, farm size does not have any significant effect on efficiency. The reason for that could be that two affects can offset each other. Normally, we should expect higher efficiency from larger farms since they apply the technology, irrigation and 
management in a better way. However, cotton is such a crop that needs to be handled with care. Smaller farms are family farms and we expect to see them harvesting cotton with care.

\section{Conclusion}

This study measures the technical efficiency of cotton production incorporating the effect of premium payments to farmers. Production decisions do not depend on the market prices only, but also support policies since support policies affect the cost measures. We use stochastic frontier model in calculating the efficiencies, therefore incorporate support premium payments as one of the background variables to capture the effect of premiums on efficiency scores for cotton production. The premium payments found to be the most important determinant of inefficiencies, and the results of our analysis suggest that premiums paid to farmers increase efficiency for cotton production.

The mean efficiency is estimated around $65 \%$ for cotton production when 8 years and 14 cities are taken into account. Some examples of efficiency studies for cotton production are Binici et al. (2006) and Gul et al. (2009), where both studies calculated efficiency scores of $79 \%$. Although one can claim such differences may depend on the sample differences and climatic conditions that vary during the time period, our analysis show that the omission of premium payment factor from the regression as well may produce such difference between the efficiency scores. Thus, we suggest that the reason for higher values can be the omitted factors in the analysis.

The prices of cotton in international markets decreased between 2005 and 2007 following about thirty percent increase in cotton production between 2003 and 2007. However, in the last two years we observe cotton prices increasing. This is a result of decreased acreages for cotton in the USA and negative climate effects in India and Australia. This is reflected in the cotton prices already, as cotton prices are increased more than forty percent. It is expected a fifteen percent decrease in the world cotton production in the near future. Today, the price of cotton increased from $0.85 \mathrm{TL} / \mathrm{kg}$ in 2008 to $1.3 \mathrm{TL} / \mathrm{kg}$ (Izmir Mercantile Exchange ${ }^{8}$ ). As a result of increase in cotton prices, it is expected to see a twenty percent increase in acreage for cotton in 2010 in Turkey. It would be interesting to see the effect of premium payments in efficiency of cotton production in Turkey along with the reversed global effects.

\section{References}

Alemdar T, Oren MN (2006) Determinants of technical efficiency of wheat farming in Southeastern Anatolia, Turkey: a non-parametric technical efficiency analysis. J Appl Sci 6(4):827-830

Battese GE, Coelli TJ (1992) Frontier production functions, technical efficiency and panel data: with application to paddy farmers in India. J Prod Anal 3:153-169

Battese GE, Coelli TJ (1995) A model for technical inefficiency effects in a stochastic frontier production function for panel data. Empirical Econ 20:325-332

\footnotetext{
${ }^{8}$ http://www.itb.org.tr/en/Default.asp.
} 
Binici T, Zoulaf C, Kacira OO, Karli B (2006) Assessing the efficiency of cotton production on the Harran plain Turkey. Outlook Agr 35(3):227-232

Coelli TJ (1996) A guide to FRONTIER version 4.1: a computer program for stochastic frontier production and cost function estimation, CEPA working paper No. 96/7. Department of Econometrics, University of New England, Armidale

Coelli TJ, Prasada Rao DS, O’Donnell CJ, Battese GE (2005) An introduction to efficiency and productivity ANALYSIS, 2nd edn. Springer, New York

Gul M, Koc B, Dagistan M, Parlakay O (2009) Determination of technical efficiency in cotton growing farms in Turkey: a case study of Cukurova region. Afr J Agric Res 4(10):944-949

Kilic O, Binici T, Zulauf CR (2009) Assessing the efficiency of hazelnut production. Afr J Agric Res 4(8):695-700

Kumbhakar S, Knox Lovell CA (2003) Stochastic frontier analysis. Cambridge University Press, Cambridge 